\title{
Done But Not Published: The Dissertation Journeys of Roy J. Lewicki and J. Keith Murnighan
}

\author{
Shirli Kopelman, ${ }^{1}$ Anne L. Lytle, ${ }^{2}$ Cynthia S. Wang, ${ }^{3}$ Roy J. Lewicki, ${ }^{4}$ \\ J. Keith Murnighan, ${ }^{5}$ and Max H. Bazerman ${ }^{6}$ \\ 1 Ross School of Business, University of Michigan, Ann Arbor, MI, U.S.A. \\ 2 Monash Business School, Monash University, Melbourne, Vic., Australia \\ 3 Spears School of Business, Oklahoma State University, Stillwater, OK, U.S.A. \\ 4 Max M. Fisher College of Business, The Ohio State University, Columbus, OH, U.S.A. \\ 5 Kellogg School of Management, Northwestern University, Evanston, IL, U.S.A. \\ 6 Harvard University, Boston, MA, U.S.A.
}

\section{Keywords \\ academic achievement, career, conflict management, dissertation, doctoral student, graduate education, escalation of commitment, negotiation, perseverance, publication, research productivity.}

\section{Correspondence}

Shirli Kopelman, Department of Management and

Organizations, Ross School of Business, University of Michigan, 701 Tappan Street Ann Arbor, Ml 48109-1234, U.S.A.; e-mail: shirli@umich. edu.

\begin{abstract}
This article explores the tumultuous path to publication that begins for many of us with trying to publish our dissertation. We invited Roy J. Lewicki and J. Keith Murnighan - the 2013 and 2015 recipients of the International Association for Conflict Management (IACM) Lifetime Achievement Award-to reflect on this process, as neither of them were successful in getting their dissertation articles published. We also asked them to reflect on the twists and turns of academic publishing, and we asked Max Bazerman to integrate these reflections. Together, we hope to spark generative conversations that will enable scholars to successfully navigate their academic careers.
\end{abstract}

"A good dissertation is a done dissertation." This sentence is sage advice, and something that many Ph.D. students hear when mentors and friends encourage them to focus on completing their thesis. Defending a dissertation and earning a Ph.D. are tremendous academic accomplishments that represent a critical first step in an academic career. Publishing it becomes an immediate next target.

At the 28th annual conference of the International Association for Conflict Management (IACM), June 28 to July 12015 in Clearwater Beach, Florida, U.S.A., we were surprised to discover that our two most recent recipients of the IACM Lifetime Achievement Award (LAA) were not successful in getting their dissertations published. Both Roy Lewicki (IACM LAA 2013) and Keith Murnighan (IACM LAA 2015) achieved extraordinary success with far-reaching impact in both research and practice, but neither

This article was inspired by conversations at the 28th Annual IACM Conference in Clearwater Beach, Florida, U.S.A. (June 28 to July 1, 2015). Shirli Kopelman (IACM Executive Director and President-Elect), Anne Lytle (IACM President and Conference Host), and Cynthia Wang (IACM Conference Program Chair), who worked together to produce the 2015 IACM Conference, invited Roy Lewicki and Keith Murnighan to share insights on their dissertation journeys, and they asked Max Bazerman to integrate their reflections about the twists and turns of academic publishing. These wonderful conversations continued over the months of July and August of 2015 while we worked with Deborah Cai, NCMR Editor, to craft them into an article. 
of them had easy starts to their careers. We were curious to learn more about their failed dissertation journeys and the insights they might offer to doctoral students and junior faculty.

The goal of this article is twofold. First, Roy and Keith will symbolically publish their dissertations (Lewicki, 1969; Murnighan, 1974) by sharing a snapshot of the theoretical and empirical contributions of their doctoral research. Second, we have asked them explicit questions about their experiences in hopes of generating insights about our field that will benefit scholars embarking on an academic career.

This article is set in a conversational style, with questions and answers (Q\&A) for Roy and Keith. Max Bazerman integrates their reflections to push these ideas further. We begin each Q\&A section with a brief summary of Roy's and Keith's professional accomplishments. Both Roy and Keith have had extraordinary careers, and among their many accomplishments, they have both repeatedly been successful at mentoring doctoral students and junior colleagues. In fact, their commitment to junior scholars has been unwavering and long-standing. We hope that you, as a reader, will be touched by their candidness and generosity in a way that enables you and your immediate community of scholars to thrive.

\section{Q\&A with Roy Lewicki-August 2015}

Roy J. Lewicki is the Irving Abramowitz Memorial Professor Emeritus of Management and Human Resources at the Ohio State Max M. Fisher College of Business in Columbus, OH, U.S.A. Roy received the IACM Lifetime Achievement Award in 2013. A longtime member and former IACM President, Roy is a familiar friendly face to IACM members, and he has an incredible list of achievements. Roy has published 36 books and over 43 articles in the areas of negotiation and conflict management, interpersonal trust, framing dynamics in environmental dispute resolution, ethics, organizational justice, and leadership. His many awards include best article and book awards from the IACM, the International Communication Association, and the Journal of Organizational Behavior. In addition to his impressive research record, Roy has received many accolades for his work in teaching and education. He is well known for his collection of textbooks (Negotiation; Negotiation: Readings, Exercises, and Cases; Essentials of Negotiation) first published in 1985 and now in their 7th editions (McGraw-Hill). He has received the Distinguished Educator Award from the Academy of Management (AOM) and multiple Outstanding Professor teaching and service awards from his home university. He was founding editor of the Academy of Management Learning and Education journal and has served regularly on the editorial boards of major academic journals, including the Journal of Management, Journal of Management Education, Academy of Management Learning and Education, Organizational Behavior and Human Decision Processes, Negotiation Journal, and Negotiation and Conflict Management Research. Roy appears regularly in teaching-related professional development workshops at the AOM and IACM conferences, and he designs and delivers executive training programs on negotiation, conflict management, and general management to a wide range of international corporations, as well as local organizations around Columbus, Ohio.

\section{Where and when did you pursue your Ph.D., and who were your mentors?}

I did my undergraduate work at Dartmouth. I majored in psychology, because I had become fascinated with small group dynamics and leadership, largely through an early experience with a t-group workshop for college students at the National Training Laboratories in Bethel, Maine. The lab had been recommended to me by two of my favorite high school teachers - one in social studies, the other in math - who thought I would benefit from it. At Dartmouth, I did research projects with a social psychologist, Lloyd Strickland, and published several lab studies with him.

I decided I wanted to go to graduate school, and applied to several. I was fortunate enough to get into a social psychology program at Teachers College, Columbia University. I picked the program because the faculty were doing both laboratory research as well as applied social psychology projects in schools and communities (the early stages of what became the field of Organizational Development). I was incredibly fortunate to work with Morton Deutsch, an eminent social psychologist 
studying conflict processes. Those were exciting years at Columbia, because we were creating conflict studies in the research laboratory while the civil rights and antiwar movements boiled around us in the streets of Manhattan. (It was the Sixties, for crying out loud!) Deutsch and my high school math teacher, Maurine Failey, have remained some of my most important mentors ever since then. Fifty years of Deutsch's doctoral students just feted him with an all-day event for his 95th birthday this past April of 2015.

\section{What was the theoretical and empirical contribution of your doctoral dissertation?}

Most of the research in Deutsch's lab focused on questions of conflict escalation and conflict resolution. We drew from Deutsch's own early research on conflict, cooperation and trust, from other early social psychologists, such as John Thibaut and Harold Kelley, and from writing in game theory and political science, including Thomas Schelling and Anatol Rapoport. Walton and McKersie had just been published, and their theories of distributive and integrative bargaining opened a lot of doors. Methodologically, we worked with a bargaining game Deutsch had invented called the Acme-Bolt Trucking Game, with prisoner's dilemma (PD)-type games, and with several new laboratory games we invented to do a better job of discriminating cooperative versus competitive and offensive versus defensive choices in PD-type games.

The title of my dissertation was The Effects of Cooperative and Exploitative Relationships on Subsequent Interpersonal Relations. Its purpose was to see if an individual's cooperative or competitive experience with a party influenced his or her subsequent cooperative or competitive behavior with others, independent of personality differences. This was a lab study in which I created an extended PD-type laboratory game in which experimental subjects played against a confederate (the experimenter), who either allowed the subject to successfully take advantage of him or cooperate with him. The research question was whether a successful cooperative or exploitative experience in the first game would affect the subject's orientation to a second player (whether the first experience generalized to the second). Perceived similarity or dissimilarity of the first and second other party was also manipulated. The potential theoretical contribution was that successful exploitative or cooperative experiences generalized to other relationships, and the potential methodological contribution was that I was able to decompose the choice options in the PD game to explicitly signal exploitative, individualistic, and cooperative intentions toward the other party.

Why wasn't your dissertation published? If you could be objective, what hurdles prevented your dissertation from being published within the first few years of your career?

While the hypotheses were confirmed, there were numerous alternative explanations to the results that could not be ruled out. My committee and I discussed these extensively, but they did not ask me to collect additional data. In addition, by the time I completed and defended my dissertation, I was 6 months into my first job and completely absorbed by preparing new courses (I had no significant teaching experience as a doctoral student). By the time I got the study written up, I sent it out to two different journals, each identified the same limitations I knew about. Since the facility where I took my first job had no easily available experimental lab (I had moved from a social psychology program to an applied organizational behavior program), it was difficult for me to run more subjects, and I eventually just gave up on trying to get the dissertation published.

You did some of the early research on escalation of commitment. How do you think about the topic of escalation in this context? When did you abandon ship and give up trying to publish your dissertation research? Did you quit too late or too early?

My research on escalation of commitment actually was pre- and post-dissertation research. In the pre-dissertation study, I worked with Deutsch on a study of the role of commitment in a game of chicken using the Acme-Bolt trucking game. For those for whom this game is something out of ancient history, this was a bilateral negotiation game in which two parties had to move electronic 
trucks toward destinations on the opposite side of the game board while sharing a one-lane section of the road. The sooner they moved their truck from start to finish, the more money they made, so parties had to negotiate on how to share the one lane section (usually by agreeing to a tit-for-tat sequential coordination plan for priority on the one lane section). The game leant itself to studying variables such as conflict size (the length of the one lane section), game playing strategies, and various strategic communications, such as threats, offers, deception, face saving, and commitments. Following the theoretical work of Thomas Schelling on commitment strategies in international negotiations (this was during the Cold War), Deutsch and I did a study on the efficacy of unilateral commitments by one player on game behavior and payoffs. It was fascinating to see how quickly parties escalated into stalemate and how difficult it was for them to communicate and discover ways to de-escalate the conflict. By the way, although Acme Bolt declined as a research tool because of several limitations in the structure of the game, it continued for years as a tool used by marital therapists to diagnose communication breakdowns between married couples and ways to intervene to improve their conflict management skills.

I returned to the study of commitment in the mid-1980s after I had read Alan Teger's Too Much Invested to Quit. My fellow doctoral student and colleague, Jeff Rubin, and I talked about this a lot (Jeff eventually did several studies on commitment with his doctoral student, Joel Brockner). At the same time, I was drawing on escalation research to study bad loan psychology (the tendency for banks to loan more money to failed loans, in the hope that greater commitments would turn the loan around from a failure to a success). This theme evolved into extensive work on commitment and entrapment as a cognitive bias. Obviously, escalation of commitment is still a huge practical problem in military thinking, financial investment, and risky decision making-we have learned a lot on the research side, but it doesn't translate into practice often enough!

The themes of escalation of commitment continue to run through cases and role plays I have written. And I have greatly benefited from Keith's experience with the Dollar Auction, which both of us have used with phenomenal success as a teaching tool about the perils of escalation of commitment.

\section{How has the field developed and changed over the span of your career? What was the field like at the} time of your dissertation?

I don't think I can count all the ways that the field has changed. I completed my degree in 1969; in social psychology. At the time, most of the conflict and negotiation research was conducted using simple laboratory games like Prisoner's Dilemma, manipulating variables such as game structure and personality differences. By the late 1970s, this research tradition was (deservedly) dying. And since I had chosen to move toward a more applied professional community, I spent most of my early teaching years learning organizational behavior and ways to study conflict and negotiation in more applied settings. In the late 1970s and early 1980s, the field began to change dramatically; while social psychology research in conflict was on the wane, the applied disciplines of management, law, public policy and international relations fueled the continued growth. Seminal events included the founding of applied negotiation courses in business schools and law schools, the Hewlett Foundation's funding of centers in multiple disciplines to underwrite research and teaching (including doctoral programs) in applied dispute resolution, and the creation of new journals like the Negotiation Journal, the International Journal of Conflict Management, and Negotiation and Conflict Management Research. The field has genuinely become far more interdisciplinary-both theoretically and methodologically-and there are currently many research outlets for all types of theoretical and methodological approaches. Clearly, I am happy with these changes, although I think the field still needs significant maturation to better integrate the lab study versus field study approaches and results. Good field study work is still far more difficult and time consuming to do than lab studies, but we need to continue to encourage more field research. 


\section{If you could reinvent the publication process, how would you redesign the review process and journal} outlets to enable greatest impact?

I don't have a great answer to this question. Any subjective, peer review process is bound to be fraught with Type I and Type II errors. What I would like to see is more diversity in online journals, blogs, commentaries, etc., that allow for briefer papers that talk about an interesting idea, explore a problem quickly, report interesting data in search of an explanation, and so on. (Some online mechanisms for communicating research now seem to be partially remedying this problem). I also think that many good research ideas get swamped and drowned in the editorial review process, in which critiques about methodological sophistication and nuance kill some incredibly interesting research ideas. I'd rather see some journals translate some of the good symposia from IACM and AOM into print: 6-8 pages summaries of several thematically-similar research papers, followed by the insightful comments of a discussant. Discussants are often the most interesting part of a meeting symposium, but their ideas get completely washed out by the time articles get accepted in a journal.

What tips have your graduate students found most helpful in mitigating the frustrations (stated mildly) we all experience when facing the review process and connecting to the aesthetic beauty and positive emotions when we imagine (and hopefully experience) success?

The fascinating thing about the research and review process is that it often represents the highs and lows of the world's best roller coasters. At the outset, you are excited about the process of climbing some exciting hill or clearing some new conceptual forest, and have great hopes and expectations about the quality of the data you will get or the reception the study will get when submitted for review. Unfortunately, the low point is not when the study doesn't work - i.e., we don't get the results we hoped for-but instead, when the hard work we put into it is ignored by reviewers and replaced with superficial, picky, or irrelevant critiques. This comment may come across as arrogant, but in my view, too many reviewers are incapable of evaluating the quality of a good idea that may be less-thanwell executed, and instead favor the presentation of an average 'me too' study that is well executed. Many journals are simply too full of these studies. I don't think there is any way to insulate doctoral students from this - all we can do is prepare them for the fact that reviewers seldom meet our expectations, that research (like Moneyball) is a game of persistence and percentages, and that the best strategy after receiving reviewer feedback is to scan the review, lock it in a desk for at least 72 hours until you cool off, and then go back and see if you can derive helpful guidance from whatever is being said. Also, write for different outlets. Would you rather do four revisions of the same article for a top journal, or get four successful hits in slightly less prestigious outlets? Since many of us work at institutions where no conflict or negotiation journals are among the top ten on the promotion and tenure committee's short list, some of us have to take risks to find other ways to both see ourselves as successful and eventually be acknowledged by our hiring institution.

Do you have a favorite place to write that enables you?

I write at home, and particularly when I am starting a paper or working on a tightly reasoned argument, I try to write in the early morning when my head is clear. No matter how much I write, starting a new paper is always difficult for me, because I still have those little demons in the back of my head talking to me saying, 'You don't know what you are talking about' or 'this is a dumb idea' or 'is anybody really going to want to read this?' I try to get some things down on paper before the demons wake up (they tend to sleep in). Sometimes I write with noise in the background-e.g., news TVwhile other times, I need silence. Chocolate and coffee are important fuels to have on hand. Many times, I need the panic created by a deadline to get me focused.

We also have a vacation house in New England, which is a beautiful place to write, early in the morning out with a laptop and coffee on the deck overlooking the pond. In the winter, the same stoic silence of the cold and snow is equally inspirational. 
One of the things that students and young faculty must learn is how to experiment with when and where they write most easily, to get over the natural blocks, and fight their demons. You can't give advice to anyone else; everyone has to experiment with the specific times and places where they are most productive. Find those times and spaces, and protect them aggressively from outside invaders.

\section{Q\&A with Keith Murnighan-August 2015}

J. Keith Murnighan is the Harold H. Hines Jr. Distinguished Professor of Risk Management at the Kellogg School of Management at Northwestern University in Evanston, IL, U.S.A. Keith received the IACM Lifetime Achievement Award in 2015. As a long-time member of IACM, Keith embraces the mission of the lifetime achievement award, with his immeasurable ability to span disciplinary boundaries in his work. His work has been on the forefront of the fields of social psychology, organizational behavior, and economics. In a career spanning more than 40 years, Keith has published seven books and over 130 articles on topics ranging across negotiation, bargaining, decision-making, ethics, conflict management, interpersonal trust, diversity, and leadership. He has won numerous accolades for his work, including the IACM Outstanding Book Award (2014) for his book, Do Nothing! How to Stop OverManaging and Become a Great Leader (Portfolio/Penguin). In this book, reflecting on the recurrent theme of trust across much of his research over the years, Keith challenges leaders to empower their teams to do their jobs without leader interference. Keith's contributions are even more impressive when we examine his dedication to disseminating this knowledge, ranging from winning countless teaching awards to being recognized, like Roy, with the AOM Distinguished Educator Award for his excellence in mentoring and creating a continuing stream of successful scholars. And also like Roy, Keith designs and delivers executive training programs translating this knowledge to practice for leaders and organizations around the world.

\section{Where and when did you pursue your Ph.D., and who were your mentors?}

I did both my undergraduate and graduate work at Purdue University, finishing in 1970 and 1974, respectively. I know that's not recommended, but I switched majors, from Math to Psych, after 2 years, and it turned out that I had a grand total of one elective in 4 years as an undergrad. So there was plenty for me to learn in the Social Psychology grad program.

My advisor was a newly christened associate professor, Carl H. Castore. Carl and his wife lived in the same apartment building that my wife and I lived in, and after asking him, when I was an undergrad, if he had any research projects I might help on, we established a strong professional relationship (as well as a friendship). Over time I realized that Carl had a number of personal problems, not of his own making. As a result, he never was promoted to full professor. In 1974, I completed my Ph.D. at Purdue and took a job as an assistant professor at the University of Illinois Urbana-Champaign. The title of my dissertation: Coalition Behavior in Decision Making Groups.

\section{What was the theoretical and empirical contribution of your doctoral dissertation?}

Carl and I had been doing work on 5-person decision making groups in the lab. I ran literally hundreds of groups for a couple of our different research projects. I noticed that a subset of the group members seemed to dominate intragroup discussions, and I wondered if I could document the formation of implicit coalitions within these groups and show that these implicit coalitions' preferences determined the groups' decisions.

I reviewed the literature on coalitions in psychology, sociology, and political science. (Experimental economics did not exist at that time.) I then tried to propose a theory of coalition behavior in decision making groups. After making a series of assumptions (e.g., that people are motivated by both cooperation and competition), I suggested that the primary causal force in coalition forming behavior was the group members' expectations of a coalition's outcomes, both short and long term. I tried to 
identify a host of possible, relevant outcomes, as well as a long list of contextual factors, that would influence the coalition formation process. Ultimately, I predicted the following: that the coalition that can obtain the maximum outcome while minimizing both its size and its ideological range will be the coalition that is most likely to form. I also included a set of more particular hypotheses, e.g., I predicted that the minority should have a greater impact on the decision as diversity within the group increases.

The results indicated that groups with more diverse individual preferences were more likely to form implicit coalitions to make their group decision. Potential coalitions of the three or four most similar group members, however, did not appear to form. Implicit three-person coalitions were not more influential than implicit four-person coalitions, and the presence of women in the group made implicit four-person coalitions more likely. It also appeared that males with divergent preferences (i.e., not similar to the other coalition members' preferences) were more likely to join the winning coalition than women with divergent preferences. After their group decisions, members of the winning coalition displayed more satisfaction and behavioral commitment to the group than non-members did.

What was important about this study? I think that I was successful in documenting the formation of effective, implicit coalitions within 5-person decision making groups, but the membership of these implicit coalitions did not depend on similar preferences. Instead they seemed to depend on men dominating women during their group discussions. This fit an early theory by Vinacke (summarized in Gamson, 1964), that women in coalition situations tended to display accommodative behavior and men tended to display exploitative behavior.

Why wasn't your dissertation published? If you could be objective, what hurdles prevented your dissertation from being published within the first few years of your career?

In retrospect, I think that the research was competently conducted, but the findings were far from earth-shattering. Thus, I think the work really did not contribute as much as it might have. The notion of implicit coalitions was not totally unexpected, and the male-female differences that I observed in the coalition-formation process were not new.

In your keynote address at IACM 2015, you emphasized perseverance, or as you frame and pronounce it: "per-sever." Publishing research in academic journals frequently requires perseverance. Yet, perseverance seems like the opposite of escalation of commitment. How do you strike a balance? And, did you quit too early or too late?

Sometimes I think we only know that we have escalated after we have beaten our heads against the wall too many times without success. That was the case with my dissertation. I submitted it to seven or eight different journals before I quit. (Part of the reason was that I wanted to get the findings out there so that no one else would be tempted to do the same research. I really didn't want anyone to reinvent a wheel that had already been discovered.) On at least three or four occasions, I was offered the opportunity to revise and resubmit my paper. But each time, the result was the same. I remember that I even argued with some of the editors, via snail mail, as there was no email at the time. I really did think that the paper was worthy of publication. But I clearly was wrong.

Was this escalation of commitment? In retrospect, I would have to say, "Yes." But would I do it again? I would also say, "Yes."

I don't believe that I am smarter than the average academic. But I do believe that I have thicker skin. Whether this is genetic or learned, I try to persevere in many arenas. When the going gets tough, I have found that, especially in academic endeavors, perseverance pays. This is not dogged repetition. Instead, it involves both thought and effort that is based on dedication to a goal that you believe is worthwhile. It's a never-give-up attitude combined with a bit of problem solving that often separates successful from unsuccessful academics.

Perseverance and its effects on academic success are also a demonstration of something that we teach in negotiations: QTIPS, i.e., quit taking it personally. Negotiators are trying to do well for 
themselves, and journals are trying to do well for themselves, too. If your paper doesn't quite fit their mission or their style, or if it doesn't quite reach their idiosyncratic standards, it doesn't say anything about you as a person. It's just that this particular paper is not going to make it in this journal this time. One of the many wonderful things about our field is that we have many, many publication outlets. So after every rejection (and I have had hundreds), there is almost always another outlet to pursue.

How has the field developed and changed over the span of your career? What was the field like at the time of your dissertation?

This is a big question, one that could require a huge response. Social psychology has clearly changed in many ways, as has organizational behavior. And experimental economics now exists. There have been many good changes, e.g., an expectation that one study cannot really answer a question very thoroughly, that underlying mechanisms can be identified, and should be, and that researchers actually take care to avoid tempting biases in the conduct of their research.

Some of the negatives, however, include a narrow focus on esoteric questions, i.e., not thinking about or looking at the big picture, both in terms of the research that people are doing and the research that journals are publishing. It no longer seems that a great new idea has much of a chance, unless the authors conduct a tour de force of seven studies with multiple dependent variables and widely varying samples. In fact, at the moment, the flagship journal of the Academy of Management won't even review a paper that includes student subjects. Thus, while social psychology has done its best to reign in data falsification and other questionable scientific practices, organizational behavior seems to have rejected a basic methodology-laboratory experiments - without providing any justification for doing so. This is particularly troubling.

If you could reinvent the publication process, how would you redesign the review process and journal outlets to enable greatest impact?

I applaud the recent movement towards careful research that reveals all of a researcher's dependent variables and all of a project's studies. I applaud the push to run studies with larger sample sizes, and to avoid peeking at the data to determine whether a subset of the entire sample might achieve significant results.

If I were the Editor of All Social Science Journals (a role that I adopt in my Ph.D. seminars), I would ask researchers to report all of the studies that they have done on a project-in chronological order. Far too often research reports come across as prescient, masterfully conducted symphonies when, instead, they were staccato-ridden discoveries that turned left, turned right, and went back to cover something overlooked before progressing to a final, well-informed, well-constructed study that nails the phenomena, broadly and effectively. By presenting studies chronologically, researchers cannot only document their findings neatly, but they can also display the nonlinear process that social science research so often takes. It's incredibly rare for researchers to design the best set of studies on a topic right off the bat; instead, they typically do less-than-ideal studies first and only after these studies have given them new insights are they then able to really address a question effectively.

What tips have your graduate students found most helpful in mitigating the frustrations (stated mildly) we all experience when facing the review process and connecting to the aesthetic beauty and positive emotions when we imagine (and hopefully experience) success?

I often write with younger colleagues, and we often have our papers rejected. In fact, getting rejected is such a common event in my life that I can tell my co-authors that it is highly likely and that it should not trouble us. In particular, I tell them we simply have to find the right combination of our text and three or four supporters who happen to be our reviewers. If it takes three or four submissions (or more) for that to happen, c'est la vie. It pays to keep trying. 
Note: the above paragraph outlines what I think I should do, and what I often try to do. My Irish temper often surfaces after a rejection, however, so all bets are off-reviewers are dense, editors are limited, and the field is not really worthy of our outstanding research!

Thus, as was noted at the conference, I do get angry at reviewers who are close-minded, dogmatic, or dense. I love reviews that are thoughtful and constructively critical, however, even when a paper is rejected. Anyone who can tell us something that will help us improve our work has done us a favor, especially since, for the most part, our papers usually do get published, and their comments make our final product better.

\section{Do you have a favorite place to write that enables you?}

I write at my office at school. I have a nice keyboard and a big screen, and I'm surrounded by an amazing group of colleagues and graduate students. In other words, it's a great atmosphere and, when I have trouble with an idea or some text, I always have someone nearby who can help. I also have a drawer full of snacks (nuts and chocolate for the most part) and a small refrigerator (with Coke and beer in it), so I can fortify myself whenever I need to as well.

\section{Integrative Comments by Max Bazerman}

My comments are far from unbiased. Roy and Keith are both great friends, have been my mentors for years, and are two of my favorite people in the field. Their generosity and insight come through in the paragraphs above. Roy and Keith are also very different people, who have influenced our field in different ways. Yet, there are some amazing commonalities. They were both trained as basic social psychologists, yet ended up having enormous influence by mentoring people who are now the leaders in our more applied field. They both are wonderful people, who have focused on the careers of others, in ways that made their own journey more intriguing, powerful, and enjoyable.

They both increase their influence by being open to the changes created by the next generation. Their comments on the changes that have occurred over the last 40 years are fascinating. Yet, unlike many at or near retirement, they do not think that they should have veto power on how our field develops. Just the opposite, they are both fascinated by the changes and value the dynamism of our field.

As someone who earlier studied escalation of commitment (but did not escalate my commitment to that work), I found the dialogue on perseverance and escalation fascinating. How can we recommend perseverance while also recommending against escalation of commitment? I think both Roy and Keith provide role models to the answer to this apparent paradox. Clearly, young researchers without perseverance are unlikely to emerge as leading scholars. Both Roy and Keith highlight their experience with getting articles rejected (by the way, I would bet either of them that I have had more rejection letters than either of them, despite being a bit younger). Yet, they both highlight valuing perseverance and continuing in the face of adversity, without escalating commitment when your time and other resources would be better invested elsewhere. Interestingly, both the lack of perseverance and escalation are more likely to result from emotive processing, while making an assessment of where you should best allocate your resources is a much more deliberative thought process (Kahneman, 2011).

I have obtained so much value from my friendships with Roy and with Keith. And I know that this is true for hundreds of others. So, I think that we should all be grateful for their rejected dissertations. What would have happened if their articles had been easily accepted? Roy could have kept Acme-Bolt alive for decades. And Keith might still be running abstract coalition games in the laboratory. These are worthy pursuits, but paths that may have not led them to connect to our field in its current form. Or imagine that they continued to send out the work, getting it rejected a bunch more, got frustrated with the publishing process, and took their talents in other directions (Roy as a Dean?; Keith as a Photographer?). Based on what I know about them, they still 
would have found paths to great lives, but they may have been different lives, in different subfields, and with different networks. And those of us who value them so tremendously would have missed out. So, to those reviewers who rejected the work of Lewicki and Murnighan, we thank you. We would not want to recreate history and run the risk that we would have had less access to their brilliant careers and to their friendship.

\section{Summary}

Thank you indeed to those reviewers who rejected the dissertation work of Lewicki and Murnighan! And thank you Roy and Keith for walking your path and sharing your insights.

It turns out you can have an outstanding career without publishing your dissertation research. Of course, we are sampling on the dependent variable here, but we were astounded when a casual conversation at a conference brought to light that two recent lifetime award researchers peaked the scales of success, despite failing to publish their dissertations. We genuinely hope the conversations shared here will help scholars at all career stages. They might help junior scholars mindfully navigate how long to persevere and when to consider a project a sunk cost, let it go, and prioritize other work. For more senior scholars, these conversations might reveal that you stand in good company and that a career is not indelibly tarnished if it did not start with a published dissertation. And for everyone, we hope this article sparks conversations that enable all of us to continuously reinforce positive relationships and cocreate an embracing and generative academic culture.

\section{References}

Gamson, W.A. (1964). Experimental studies of coalition behavior. In L. Berkowitz (Ed.), Advances in experimental social psychology, Vol. 1 (pp. 81-110). New York, NY: Academic Press.

Kahneman, D. (2011). Thinking, fast and slow. New York, NY: Farrar, Straus \& Giroux.

Lewicki, R.J. (1969). The effects of cooperative and exploitative relationships on subsequent interpersonal relations. Unpublished dissertation, Columbia University, New York, NY, U.S.A.

Murnighan, J.K. (1974). Coalition behavior in decision making groups. Unpublished dissertation, Purdue University, West Lafayette, IN, U.S.A.

Shirli Kopelman is a professor of Management \& Organizations at the University of Michigan's Ross School of Business. She studies emotions in negotiations and decision-making in social dilemmas. Shirli Kopelman is author of Negotiating Genuinely: Being Yourself in Business, published in 2014 by Stanford University Press.

Anne L. Lytle is Professor and Director of Leadership at Monash University's Business School. Her research, training, and consulting focus on the influence of culture in negotiations and conflict management, creating positive organizational cultures, and managing people for high performance.

Cynthia S. Wang is an associate professor of management and the William S. Spears Chair at the Spears School of Business at Oklahoma State University. She received her doctorate from Northwestern University. Her research explores two challenges that are particularly relevant in increasingly globalized organizations: understanding how to diminish unethical behavior and how to effectively navigate diverse environments.

Roy J. Lewicki is the Irving Abramowitz Memorial Professor of Management and Human Resources Emeritus at the Max M. Fisher College of Business, The Ohio State University. His research focuses on trust and trust repair, negotiation, and conflict management. He is the co-author of market-leading 
textbooks Negotiation, Negotiation: Readings, Exercises, and Cases, and Essentials of Negotiation (McGrawHill) and numerous articles on trust, negotiation, and teaching practices in conflict management.

J. Keith Murnighan is the Harold H. Hines Jr. Distinguished Professor of Risk Management at the Kellogg School of Management, Northwestern University. He studies negotiations, teams, decision-making, trust, and ethics. His most recent book is Do Nothing! How to Stop OverManaging and Become a Great Leader (Portfolio/Penguin, 2012).

Max H. Bazerman is the Co-Director of the Center for Public Leadership (with David Gergen) at the Harvard Kennedy School and the Jesse Isidor Straus Professor of Business Administration at the Harvard Business School. His awards include an honorary doctorate from the University of London (London Business School), Aspen's Lifetime Achievement Award, and the Distinguished Educator Award and the Distinguished Scholar Award from the Academy of Management. 